\title{
The Free Improvisation Game: Performing John Zorn's Cobra
}

\author{
Dylan van der Schyff \\ University of Sheffield \\ UK
}

\begin{abstract}
The use of improvisation is wide spread in musical practice around the world. Nevertheless, Western academic circles tend to ignore this ubiquitous activity and have maintained a focus on composition and interpretation. This is beginning to change, however, and the role of improvisation in performance and music education is receiving an increasing amount of attention. This paper contributes to this project by examining the practice of 'free improvisation' in a large ensemble context. A rehearsal and performance of John Zorn's Cobra--a 'game' piece for improvisers--is analyzed from a first-person perspective; relevant research in music psychology is considered; and suggestions are made with regard to how we may better understand the nature of musical communication in improvised contexts. Pedagogical applications are also considered.
\end{abstract}

Keywords: improvisation; musical communication; music education; performance; music psychology 
This paper recounts and analyzes a performance of John Zorn's Cobra--a 'game' piece for improvisers--from a first person perspective. I examine the process of rehearsal and performance making reference to relevant literature in music psychology; and I offer some tentative possibilities for how we might understand musical communication in the context of free improvisation. To conclude I consider the pedagogical applications of the piece. While the account offered here is largely anecdotal, it is my hope that this paper may offer some useful insights into the nature of musical improvisation and perhaps inspire more sustained and rigorous inquiries into this fascinating and under-researched area of musical practice. I have checked my notes and recollection of events with others involved to ensure that my account is as accurate as possible.

\section{INTRODUCTION}

A number of years ago I received a phone call from the producer of an international new music festival in Quebec inviting me to participate in a performance of John Zorn's Cobra. Zorn himself would be conducting--or 'prompting', as the piece requires--and the ensemble would feature a "who's who" of Canadian and American improvisers coming from a variety of musical backgrounds. Although I immediately agreed to take part in the event, I was not without some apprehensions. I had participated in a number of large ensemble improvisation projects in the past. These works utilized novel approaches to conduction and notation, modular or mobile forms, as well as improvisation within constraints imposed by the composer/conductor (Bailey, 1992). And although these experiences were often interesting and educational, I found that the production of the music often ended up falling in to hierarchies that resembled the composer-conductorensemble structure of classical music (Small, 1998) or soloist-rhythm section models reminiscent of mainstream jazz (Berliner, 1994; Monson, 1996).

Of course, there is nothing wrong with these more codified musical practices per se. However, one of the great joys of free improvisation is how a good ensemble can construct and deconstruct its own structures and musical hierarchies through the moment-tomoment decisions and interactions of the members of the group--where the music the group creates is defined by the unique materials and strategies each member brings to it. While most of the large ensemble improvisation projects I had been involved in embraced this aesthetic to some degree, more often than not improvisation was used to realize the vision of a particular individual; and I noticed that players sometimes became concerned that their voices were being stifled or simply used as a means to an end. Similar issues have been documented with ensemble players in classical music environments (Allmendinger et al., 1994; see also Brown, 1986). However, these concerns may be intensified in the context of improvised music where players may spend many years developing complex and highly individual approaches to their instrument and music making. Berliner (1994) and Bailey's 
(1992) examination of this process in the context of jazz and other genres gives some idea of the personal investment required by all improvisers.

The relationship between composition and improvisation--composer and improviser--can be difficult and very few are able to navigate it in an entirely satisfying way. As a result of this, I had become skeptical about the possibility of a large ensemble improvisation concept that would allow, let alone require, individual musicians to bring the entire range of gestures, techniques and concepts acquired through years of experience and to apply them the best way they saw fit in the moment. In terms of the type of improvisation I was interested in, my attitude echoed Evan Parker's:

...[I]f anyone is dispensable in the production of music it is the score maker or the 'composer' as he is often called. My 'ideal music' is played by groups of musicians who choose one another's company and who improvise freely in relation to the precise emotional, acoustic, psychological, and other less tangible atmospheric conditions in effect at the time the music is played. (Quoted in Bailey, 1992, p. 8081)

Adding to these concerns was the fact that for the uninitiated Cobra is thought to be impossibly complex; and that Zorn himself has a reputation for being demanding and impatient. Indeed, by the time of this performance Zorn was already well established as an iconic figure in the avant-garde music scene thanks to a prolific and highly diverse body of work. Some examples include his hardcore band, Naked City (est. 1988), which used rapid 'jump cuts' between musical genres much like the technique of film montage; his concert music for chamber groups and orchestras such as Elegy (1992) and Kristallnacht (1993); his film works, including the highly acclaimed reinterpretations of Ennio Morricone's music on The Big Gundown (1985); interpretations of jazz with records like Voodoo (1986) and News for Lulu (1988); his work as a free improviser; as well as his early compositions of the mid-seventies to mid-eighties--many of which are the smaller game pieces that lead to the creation of Cobra in 1984 (see Duckworth, 1999, p. 444-476). Despite the fact that I was already familiar with much of this work I really had no idea what to expect.

\section{THE REHEARSAL: LEARNING THE GAME}

Excited and a little nervous, I arrived for rehearsal at the concert venue midmorning on the day of the performance. Zorn greeted us all warmly. He knew a few of the musicians well, all of whom had performed the piece with him a number of times already. He took the rest of us off to the side to explain the piece while the others chatted and the sound and lighting crews did their work. Although I had seen Cobra performed once before, I knew very little about it--only that it was a 'game piece' that had developed out of Zorn's previous game inspired works, such as Lacrosse (1976), Hockey (1978), Fencing (1978), 
Pool (1979); that it was supposedly very complicated; and that many improvisers I admired had performed and recorded it. There is no published score for Cobra, a fact that only adds to its mystique.

Zorn had with him a large number of cardboard cue cards with handles taped to the back of them. On the front of the cards were large letters (SX, CT, D, T, E, B, and so on), numbers $(1,2,3, \mathrm{I}, \mathrm{II}, \mathrm{III})$ and other symbols $(\mathbf{\square}, \mathbf{\square}, \mathbf{\square}, \boldsymbol{\ominus}$....). We were each given a sheet where the function of each cue card was described. The sheet contained more symbols in the form of hand gestures. We were also given headbands. As Zorn explained how the system of symbols and gestures worked I realized why the piece could not be published in the traditional way. For one thing, there is no proper score--the piece consists of a set of events cued by symbols on the cards as well as by the catalog of hand gestures on the cue sheet; the content of each event is entirely dictated by the musicians performing it. Furthermore, there is no conductor--the initiation of events is brought about by the ensemble members themselves via the 'prompter' who stands facing the ensemble (back to the audience) with the cue cards on a table in front of him; the ensemble is arranged in a semicircle facing the audience, the prompter and each other. In performance the prompter is bombarded by various cues from the ensemble, with each musician trying to get the prompter to display the symbol he or she wants to initiate the next event. And while it is impossible for the prompter to be completely impartial, it is largely for the musicians to decide which type of cue will provide the most interesting continuation of events.

For example, one musician might hold one hand over his mouth while displaying four fingers with the other hand, meaning that he wants the 'sub crossfade' event to take place. If the prompter notices him first the 'SX' card will be displayed to the ensemble and those who are playing fade out while those who are not playing fade in. Another musician, hearing something she likes, might place one hand on her head and hold up one finger with the other hand cueing the prompter to display the ' 1 ' card. This card initiates the 'sound memory 1' event where musicians are to remember what they are playing th that moment and be able to immediately reproduce and repeat it for an extended period the next time the ' 1 ' card is displayed. A myriad of other possible events may be cued, such as duo and trio combinations or different types of endings; donning the headband signals that the musician has decided to temporarily do as they please--a renegade action that may elicit reactionary responses from the ensemble.

By the time Zorn was finished explaining things, which he did very quickly, many of us were still looking back and forth at each other with visible signs of confusion. But Zorn didn't seem worried. He assured us that like any other game we would learn Cobra most easily by playing it; he kept reminding us, "All you have to do is play." Once on stage we were positioned so we could all see each other, but in such a way that we would not fall into typical sections; instrumentation and musical backgrounds were diverse. Zorn began the rehearsal by initiating all the cues himself, but the newbies caught on quickly and soon 
the ensemble began directing things. The cues came faster and faster, often producing incredible (and hilarious) transformations. Despite the sometimes-chaotic nature of the music produced it was almost always clear when someone made an error (e.g. misreading a cue, fading up when one should be fading down, forgetting or playing an incorrect sound memory); and it was interesting how such 'errors' were increasingly incorporated into the music as we all became more comfortable with each other and the game. Although everyone appeared to be concentrating very hard there was nonetheless a great deal of laughing during the rehearsal process.

\section{PERFORMING THE GAME}

The first thing that became apparent in performance was the degree to which Cobra pushes the limits of human information processing--i.e. "real-time sensory and perceptual coding, optimal attention allocation, event interpretation, decision-making, prediction (of the actions of others), memory storage and recall, error correction and movement control" (Pressing, 1998, p.51; see also Pressing, 1988). Indeed, I found myself forced to develop new strategies--or rework existing ones--in order to keep track of things and to contribute effectively to the development of the music. The memory cues, for example, posed a special problem that I dealt with by paying close attention to what my body was doing while the cue to create the memory was shown. I found I was most successful when I was able to create a qualitative multi-modal representation of the moment in time based on the relationship between what I was hearing, seeing and what I was doing physically with my instrument/body--a kind of "visceral self perception" (Dibben, 2004). Indeed, a number of writers have recently examined the embodied aspects of performance and memory in both classical music (Palmer, 2006) and improvisation (Sudnow, 2001; Iyer, 2002).

Some of the players in the ensemble adopted approaches similar to mine while others attempted to make more structural representations (e.g. metric, intervallic, and/or harmonic sequences; written notations). Whatever the case, the unpredictable and oftenradical nature of the music involved makes it unlikely that memory models associated with more traditional tonal music, such as 'chunking' or harmonic and melodic representation (Sloboda, 1985; Lehmann, Sloboda \& Woody, 2007), would apply to all of the memory functions a round of Cobra might demand. More apropos would be a wide-ranging view that includes notions of working memory (Baddeley, 1997), sensory memory (Gallagher, 2005; Gibson, 1966), semantic and episodic memory (Tulving, 1983), and procedural memory (Squire, 2004).

Keeping track of one's own musical trajectory while simultaneously remaining aware of the manifold visual and auditory cues continuously occurring all around was also extremely challenging. Cobra exaggerates the degree to which all music performance depends on the communication of musical and other inter-personal signs--which may 
involve physical movement, including bodily and facial gestures, as much as sound. Indeed, Runeson and Frykholm (1983) have shown that bodily movements may express mental dispositions and intentions in ways that are clearly distinguishable to onlookers. And the relevance of movement and gesture to musical expression has been examined empirically by Davidson $(1993,2005)$ and considered theoretically in a jazz context by Smith (1998) in terms of semiotics.

Furthermore, Cobra demands a deep personal understanding of one's own musical arsenal as an improviser as well as the "open skills"--the musical, technical, conceptual flexibility (Thompson \& Lehmann, 2004)--required to adapt to the complex demands of the moment: While the various cues in Cobra do signify specific event types, they are also content free; they are filled and structured in real-time by the musical material the performers bring to them; as signs they are incomplete, waiting to be achieved by the very events they initiate. This is all to say that Cobra confronts the challenging interactive semiotic process inherent in free improvisation--where the entire musical environment is continuously being enacted and re-enacted through the ongoing exchange and interpretation of sounds, actions, gestures, and signs (including highly idiosyncratic musical symbols or 'vocabulary').

With this in mind, it seems that models of musical expressivity and communication that rely on deviations from musical (structural) norms--e.g. rhythmic (Desain \& Honing, 1992), phrase-timing (Repp, 1992), melodic and harmonic structure (Lerdahl \& Jackendoff, 1996)--may not always be relevant in this context. Indeed, the complex interactive and recursive process Cobra entails, as well as the often non-idiomatic nature of free improvisation, pose serious challenges to the descriptive capacities of linear, objective or generative conceptions of musical semiotics and expressivity--which, as Clarke points out, often fall into the trap of focusing too heavily on the putative relationship between structure and expression (1995, p. 53). Perhaps more useful in discussing Cobra's semiotic environment would be an 'enactive' or 'ecological' approach such as one finds in the work of Reybrouk (2005), DeNora (2000; 2011) and Clarke (2005)--where musical meanings are constructed and deconstructed through a process of perception, specification and interaction within a given aesthetic environment; through involved lived action rather than 'objective' analysis. Johnson's (2007) discussion of musical expressivity may also be relevant here--where musical meaning is considered in terms of the creation and bodily grounding of conscious and pre-conscious metaphors that provide "the relevant logics of time and space" (i.e. music and the 'metaphorical' experience of movement).

By this view the cues might be understood as affordances or 'resources' for meaning making through which the players may create coherent musical relationships and even 'compose' (or enact) larger musical structures and environments. Indeed, I was amazed at how some of the more experienced players of Cobra were able to manipulate and transform the ensemble environment in remarkable ways. For example, at one point during 
the performance one of the guitarists, finding himself the only musician not playing, initiated the 'SX' cue (cross-fade), meaning that the ensemble fades out and only he fades in. Remembering that he had logged a memory cue earlier 'containing' a rather intense groove played by the percussion instruments, he quickly initiated the 'memory 1' cue. The percussion entered on the downbeat of the 'memory 1' card and the guitarist launched into an over the top but highly effective distortion laden solo. He then donned the headband, which allowed him to play (with tongue firmly in cheek) over the shifting backdrop of the next three events. The guitarist had created a temporary hierarchy within the game; and, seeing the comic irony in this gesture, the ensemble supported him brilliantly. The audience showed its appreciation with a flood of applause and cheers.

\section{CONCLUSION}

Discussing the performance afterwards, some of the musicians in the ensemble spoke of how the experience pushed them to re-think their improvisational process in terms of communicative efficiency. Players also discussed how Cobra plays on differences in cultural and stylistic backgrounds; and how it depends on individual personalities and unique approaches to improvising. As Zorn points out,

You need people who are aggressive, you need people who are going to be docile, you need people with a sense of humor... [I]t's more the people themselves that are important. ... Some players are really kind of conceptual, thinking about structuring a piece of music, using these signals and trying to create some kind of compositional flow in their heads spontaneously. While others are, you know, creating problems. (Quoted in Bailey, 1992, p. 77-78)

Given what I have discussed here it may not be surprising to consider that Cobra has considerable pedagogical applications. Despite its complexity, Cobra can be broken up into smaller groupings of cues that afford novice improvisers the opportunity to focus on (and discuss) basic aspects of improvisation, such as dynamics, timing, memory, distinctions between ensemble improvising and soloing, ways of listening, clarity of expression, in the moment awareness and strategies (both supportive and subversive) for keeping the music vital, as well as the development of personal materials, symbols or 'vocabulary' for improvising.

Furthermore, the non-idiomatic nature of Cobra allows musicians from various backgrounds to meet on neutral ground, where acquired techniques and attitudes may need to be reconsidered. Thus the stylistic judgments that young musicians often impose on each other (i.e. making the changes, swinging, playing 'in the pocket' etc.) may be suspended, creating an environment where more fundamental aspects of musical communication come to the foreground and where previously unconsidered approaches 
may be developed--the young be-bopper may discover something new through his encounter with the electronic improviser; the metal guitarist might gain a whole new sense of dynamic interplay through her struggle to improvise effectively with a classically trained percussionist and a vocalist trained in the South Indian Carnatic tradition.

The year following the performance discussed here, I began teaching at the Banff Center's Jazz and Creative Music Program where I directed large ensembles through the game for the first week. Not only did the experience allow students to get to know each other musically and socially in a rather unique way, it also helped them to clearly identify key issues associated with musical improvisation that they would continue to wrestle with long after their stay in the program was over. Indeed, as a musical game Cobra creates a kind of 'ritual space' (Smith, 1998) wherein key elements of free improvisation are writ large. But despite its many challenges, Cobra is inclusive: playful conflict and contestation are as important as consensus; a rock guitarist is as welcome as a be-bop saxophonist, a zheng player or a non-idiomatic improviser as long as they are all willing and able to play.

More Information:

The performance discussed in this article took place on May 16 $6^{\text {th }}, 2003$ at the Festival International de Musique Actuelle de Victoriaville, Produced by Michel Levasseur. The ensemble included: John Zorn, prompter; Sylvie Courvoisier, piano; John Oswald, sampler; Diane Labrosse, electronics; René Lussier, guitar; Dylan Van der Schyff, drums; Ron Samworth, guitar; Ikue Mori, electronics; Jamie Saft, Fender rhodes; John Medeski, Hammond B3; Trevor Dunn, electric bass; Susie Ibarra, drums; Cyro Baptista, percussion; and Marc Ribot, guitar. I have checked my recollection of events against others in the ensemble for accuracy.

An example of the Cobra cue sheet can be found on line at http://www.433.com/scores/cobra/cobra-notes.html

Excerpts from a performance of Cobra appear in Derek Bailey's 1992 four part series for $\mathrm{BBC}$, On the Edge: Improvisation in Music.

\section{REFERENCES}

Allmendinger, J., Hackman, J.R. \& Lehman, E.V. (1994). Life and work in symphony orchestras: an interim report of research findings. Report No 7, Cross-National Study of Symphony Orchestras, September 1994, 95-107.

Baddeley, A. D. (1997) Human Memory: Theory and Practice. Hove: Psychology Press.

Bailey, D. (1992). Improvisation: Its Nature and Practice. New York: Da Capo Press.

Berliner, P. (1994). Thinking in Jazz: The Infinite Art of Improvisation. Chicago: Chicago UP. 
Brown, R. (1986). Social Psychology. New York: Free Press.

Clarke, E. F. (1995). Expression in performance: generativity, perception and semiosis. In J. Rink (Ed.), The Practice of Performance: Studies in Musical Interpretation (pp.21-54). Cambridge: Cambridge UP.

Clarke, E.F. (2005). Ways of listening: An ecological approach to the perception of musical meaning. New York: Oxford UP.

Davidson, J. W. (1993). Visual perception of performance manner in the movements of solo musicians. Psychology of Music, 21(2), 103-13.

Davidson, J. W. (2005). Bodily communication in musical performance. In D. Miell, R. MacDonald \& D. J. Hargreaves (Eds.) Musical Communication (pp.215-28). Oxford: Oxford UP.

DeNora, T. (2011). Music in Action: Selected Essays in Sonic Ecology. Burlington, VT: Ashgate Publishing.

Desain, P. and Honing, H. (1992). Music, Mind and Machine. Amsterdam: Thesis Publishers.

Dibben, N. (2004). The role of peripheral feedback in emotional experience with music. Music Perception: An Interdisciplinary Journal, 22(1), 79-115.

Duckworth, W. (1999). Talking Music. New York: Da Capo Press.

Gallagher, S. (2005). How the Body Shapes the Mind. Oxford: Oxford UP.

Gibson, J.J. (1966). The Senses Considered as Perceptual Systems. Boston: Houghton Mifflin.

Iyer, V. (2002). Embodied mind, situated cognition, and expressive microtiming. Music Perception: An Interdisciplinary Journal, 19(3), 387-414.

Johnson, M. (2007). The Meaning of the Body: Aesthetics of Human Understanding. Chicago: University of Chicago Press.

Lehman, A.C, Sloboda, J.A. \& Woody, R.H. (2007). Psychology for Musicians: Understanding and Acquiring the Skills. Oxford: Oxford UP.

Lerdahl, F. \& Jackendoff, R. (1996). A Generative Theory of Tonal Music. Cambridge: MIT Press.

Monson, I. (1996). Saying Something: Jazz Improvisation and Interaction. Chicago: University of Chicago Press. 
Nettl, B. \& Russell, M (Eds.) (1998). In the Course of Performance: Studies in the World of Musical Improvisation. Chicago: University of Chicago Press.

Palmer, C. (2006). The nature of memory for music performance skills. In E. Altenmuller, M. Wiesendanger \& J. Kesselring (Eds.), Music, Motor Control, and the Brain (pp. 39-53). Oxford: Oxford UP.

Pressing, J. (1988). Improvisation: methods and models. In J. A. Sloboda (Ed.), Generative Processes in Music (pp. 129-78). Oxford: Clarendon Press.

Pressing, J. (1998). Psychological constraints on improvisational expertise and communication. In B. Nettl \& M. Russell (Eds.), In the Course of Performance: Studies in the World of Musical Improvisation (pp.47-67). Chicago: University of Chicago Press.

Repp, B.H. (1992). Diversity and commonality in music performance: An analysis of timing microstructure in Schumann's “Träumerei." Journal of the Acoustical Society of America, 92(5), 2546-2568.

Reybrouck, M. (2005). Body mind and music: Musical semantics between experiential cognition and cognitive economy. Transcultural Music Review, No. 9.

Runeson, S \& Frykholm, G. (1983). Kinematic specification of dynamics as an informational basis for person-and-action perception: Expectation, gender recognition, and deceptive Intention. Journal of Experimental Psychology, 112(4), 585-615.

Sloboda, J.A. (1985). The Musical Mind: The Cognitive Psychology of Music. Oxford: Oxford UP.

Small, C. (1998). Musicking: The Meanings of Performing and Listening. Middletown, CT: Wesleyan UP.

Smith, C. (1998). A sense of the possible: Miles Davis and the semiotics of improvisation. In B. Nettl \& M. Russell (Eds.), In the Course of Performance: Studies in the World of Musical Improvisation (pp. 261-89). Chicago: University of Chicago Press.

Squire, L.R. (2004). Memory systems of the brain: A brief history and current perspective. Neurobiology of Learning and Memory, 82(3), 171-177.

Sudnow, D. (2001) Ways of the Hand: The Organization of Improvised Conduct. A Rewritten Account. Cambridge, Mass.: MIT Press. 
Thompson, S. \& Lehmann, A. C. (2004). Strategies for sight-reading and improvising music. In A. Williamon (Ed.), Musical Excellence (pp.143-59). Oxford: Oxford UP.

Tulving, E. (1983). Elements of Episodic Memory. Oxford: The Clarendon Press. 